\title{
STAVOVI RODITELJA I ODGOJITELJA O IMPLEMENTACIJI ZAVIČAJNOSTI U KURIKULUME USTANOVA RANOG I PREDŠKOLSKOG ODGOJA
}

\author{
Davorka Kalčić \\ Dječji vrtić "Rapčići" Žminj, Republika Hrvatska
}

\begin{abstract}
Sažetak
Istarska županija 2014. godine započinje proces implementacije zavičajne nastave u kurikulum ustanova ranog i predškolskog odgoja, osnovne i srednje škole. Smisao je procesa implementacije da se sačuvaju zavičajne vrijednosti i svijest o kulturnom identitetu. Cilj je provedenog istraživanja utvrditi podržavaju li roditelji i odgojitelji implementaciju zavičajnosti u kurikulume dječjih vrtića te utvrditi utječe li odgoj i učenje zavičajnih vrijednosti pozitivno na razvoj i očuvanje kulturnog identiteta. $U$ radu se prikazuju empirijski podaci provedeni u dječjim vrtićima „Rapčići“ Žminj i „Grdelin“ Buzet. Anketnim upitnikom ispitani su roditelji djece koja pohađaju dječji vrtić i odgojitelji dječjeg vrtića. Istraživanjem je utvrđeno da u ukupnom prosječnom rezultatu stavova roditelja i odgojitelja roditelji procjenjuju važnijim uvođenje zavičajnosti u kurikulume u odnosu na odgojitelje. Odgojitelji se ne razlikuju značajnije u procjeni važnosti implementacije zavičajnosti u kurikulume vrtića, međutim u procjeni važnosti podrške ravnatelja, kolega i lokalne zajednice primijećena je značajna razlika.
\end{abstract}

Ključne riječi: djeca rane i predškolske dobi, kulturna baština, kurikulum, odgojitelji, roditelji, zavičajne vrijednosti

\section{UvoD}

Sve je teže sačuvati i povezati zavičajne vrijednosti u odnosu na modernizaciju društva, nagli ekonomski razvoj te brzi protok informacija i kapitala. Ideja o očuvanju sastavni je dio definicije kulturne baštine, a sadržana je u brojnim definicijama UNESCO-a i ICCROM-a. ${ }^{1}$ Vijeće Europe (2005) donosi okvirnu konvenciju o vrijednosti kulturne baštine za društvo u kojoj se ističe obveza priznavanja pojedinačne i zajedničke odgovornosti prema kulturnoj baštini. Nadalje, navodi i obavezu integriranja elemenata kulturne baštine na svim razinama obrazovanja. Većina zemalja članica Vijeća Europe razradi je navedene teme pristupila primjenom metode odozdo prema gore (bottom-up approach). Drugim riječima, promicanje vrijednosti kulturne baštine, njezine uloge u izgradnji miroljubivog i demokratskog društva te u procesima održivog razvoja i unapređenja kulturne raznolikosti treba krenuti od najranije dobi i kontinuirano provoditi na svim razinama formalnog obrazovanja. Učenje i razvoj djece, osobito djece rane i predškolske dobi, ne odvija se izvan konteksta obiteljske kulture i tradicijskih vrijednosti zajednice

ICCROM je međunarodni centar za proučavanje očuvanja i obnove kulturnih dobara. Međuvladina je organizacija. Temeljna joj je zadaća očuvanje kulturne baštine širom svijeta, a provodi je edukacijama, informiranjem, istraživanjem i zagovaranjem očuvanja. Cilj ICCROM-a je unaprijediti područje konzervatorsko-restauratorske djelatnosti i podići svijest o važnosti i krhkosti kulturne baštine. ICCROM je osnovan 1956. godine, a sjedište je u Italiji. ICOM je međunarodni savijet za muzeje: neprofitna je organizacija posvećena očuvanju, unaprjeđenju i komunikaciji svjetske prirodne i kulturne baštine, materijalne i nematerijalne. Osnovana je 1946. godine i ima konstruktivan status unutar UN-ova Ekonomskog i Socijalnog vijeća. Sjedište je ICOM-a u Parizu. 
u kojoj dijete živi (Windisch i sur.,2003; Townsend-Cross, 2004; Whitington, 2004; KostovićVranješ, 2015; Huang i Liu, 2017). Slijedom toga, Republika Hrvatska u travnju 2007. donosi Zakon o potvrđivanju Okvirne konvencije Vijeća Europe. Konvencija o pravima djeteta (1989. godine) ističe pravo djeteta na osobni i kulturni identitet, jezik, podrijetlo i samoostvarenje poštujući sebe i druge. Očuvanje i njegovanje kulturne i povijesne baštine kao temeljne vrijednosti sastavni je dio Nacionalnog kurikuluma ranog i predškolskog odgoja i obrazovanja (2014) u trima podpodručjima; svijet oko mene - prirodno i šire društveno okružje, kulturna baština, održivi razvoj. Dijete rane i predškolske dobi snažno iskazuje radoznalost za svijet i događanja u neposrednom okruženju, to je vrijeme kad ono usvaja vještine, stavove i ponašanja, izgrađuje svoj sustav vrijednosti koji ga prati tijekom cijelog života (UNESCO, 2008). Upravo zato je rano djetinjstvo optimalno za učenje (Katalinić, 2007; Cole i sur. 2010; Burton, 2012; Kostović-Vranješ, 2015). Istarska županija 2014. godine pokreće projekt uvrštanja zavičajnosti „Istra u očima djece - tragovima prošlosti" u kurikulume ustanova ranog i predškolskog odgoja, osnovnih i srednjih škola. Svakoj odgojno-obrazovnoj ustanovi koja sudjeluje u projektu pruža jednokratnu novčanu pomoć za tekuću godinu. Tijekom pedagoške godine Županija je organizator edukativnih skupova na kojima se susreću predstavnici županije, lokalne zajednice, praktičari i znanstvenici s ciljem razmjene iskustva i postignuća. Na kraju pedagoške 2016. godine tijekom mjeseca svibnja na stručno-znanstvenom skupu predstavljaju se projekti koji su realizirani tijekom godine.

\section{Kulturna baština}

Kultura je stvaralački proces.Može se definirati kao skup stavova, vrijednosti, uvjerenja i ponašanja koje dijeli grupa ljudi, a prenose se $s$ jedne generacije na drugu (Rubin i Menzer 2010). U Rječniku hrvatskog jezika (Anić, 2009, str. 654) kultura je definira kao „ukupnost materijalnih i duhovnih dobara, etičkih i društvenih vrijednosti, što ih je stvorilo čovječanstvo". Pojam kulturne baštine širok je i njegovo pobliže određenje teško je definirati (Šošić, 2014). ${ }^{2}$ Njezina je glavna značajka čuvanje i njegovanje svega što su nam preci ostavili kao kulturu, tradiciju, zavičajnu mudrost. Kulturna je baština „skupina dobara naslijeđenih iz prošlosti koje ljudi identificiraju, neovisno o vlasništvu, kao odraz i izričaj svojih vrijednosti, vjerovanja, znanja i tradicija koje su u stalnom procesu evoluiranja. Ona uključuje sve aspekte okoliša koji proizlaze iz međusobnog djelovanja ljudi i mjesta u vremenu. Zajednica povezana baštinom sastoji se od pojedinaca koji specifične značajke kulturne baštine drže vrijednim i žele ih, u okviru javnih akcija, očuvati i prenijeti budućim naraštajima" (Zakon o potvrđivanju Okvirne konvencije Vijeća Europe, NN, 2007, čl.2.). Kulturna baština poveznica je između naše prošlosti i budućnosti, daje nam osjećaj pripadnosti zajednici i prostoru. Čuva i oblikuje kulturni, nacionalni i osobni identitet. Europski parlament i Vijeće Europe 2018. godinu proglašava Europskom godinom kulturne baštine s ciljem potaknuti ljude na otkrivanje i istraživanje europske kulturne baštine te jačati osjećaj pripadnosti zajedničkom prostoru. Slogan Europske godine kulturne baštine glasi: Naša baština: spoj prošlosti i budućnosti (Europski parlament i Vijeće Europe, 2017). Kulturna baština može biti materijalna i nematerijalna, prirodna i digitalna i kao takva od neprocjenjive je vrijednosti za ljude i zemlju kojoj pripada. Uključivanje djece rane i predškolske dobi $\mathrm{u}$ istraživanje vlastitog kulturnog nasljeđa doprinosi očuvanju tradicijskih vrijednosti (KostovićVranješ, 2015; Cifrić, 2014; Burton, 2012), kulturnog, nacionalnog i osobnog identiteta (Kokko i Kyritsi, 2012; Cifrić, 2015; Baran i sur., 2007, prema Kostović-Vranješ, 2015), promiče interkulturalnu i međugeneracijsku suradnju te socijalnu koheziju (Kokko i Kyritsi, 2012; Del Core, 2016; Kostović-Vranješ, 2015).

\footnotetext{
2 Šošić navodi kako u međunarodnopravnoj literaturi ne postoji jedinstvena pravna definicija kulturne baštine s obzirom na složenost pojma. U članku nastoji rasvijetliti pojam kulturne baštine na međunarodnopravnoj razini.
} 


\section{Zavičajnost}

Pojam zavičajnosti autori različito definiraju. Prema Aniću (2009, str. 1822) zavičaj se najčešće povezuje $s$ mjestom rođenja te ga možemo definirati i kao osobni osjećaj pripadanja nekom mjestu, kao „emocionalnu, književnu, pedagošku, odnosno didaktičko-metodičku kategoriju, domovinu u malom, osobnu domovinu“ (Rosandić, 1975, str. 9). Zavičajna baština „predstavlja zavičajno znanje i zavičajnu mudrost. Sve što je rezultat znanja i vještina pojedinca u trenutku i vremenu na određenom prostoru, a prenosi se $s$ generacije na generaciju, predstavlja temelj za sve buduće aktivnosti u cilju očuvanja iznimnog bogatstva povjesnog identiteta" (Maretić i Caktaš, 2007, str. 89). Težeći modernom, često samo prihvaćamo nametnute, unificirane vrijednosti. Tendencija uvoza zapadnih pedagoških praksi i programa i stranog vrijednosnog sustava na kojem se temelje ne podudaraju se $s$ vrijednostima, kulturom i kontekstom u kojem se provode i kao takvi teško su održivi (Burton, 2012, Puamau, 2005). Malo dijete prirodno je i snažno povezano sa svojim zavičajem i zavičajnim jezikom s kojim odrasta i stvara čvrstu vezu između vrtića i obitelji. Uvrštanjem zavičajnosti u kurikulume djetetu se pruža prilika da istražuje i otkriva, da se čudi, mašta i zamišlja tako što upoznaje običaje i tradiciju, priče i legende zavičaja. U svojim igrama djeca se pretvaraju u vile i princeze, postaju vitezovi i neustrašivi junaci, pobjeđuju strašna čudovišta i vještice, susreću duhove i mala čarobna bića. Otvara se čitav jedan novi svijet za istraživanje i otkrivanje, razvijanje komunikacijskih vještina, suradnje i zajedničkog rješavanja problema. Pedagošku vrijednost uvođenja načela zavičajnosti u odgojno-obrazovni sustav Šimleša ističe 70 -ih godina prošlog stoljeća na Čakavskom saboru u Žminju, a sastoji se u povezanosti škole odnosno vrtića s običajima, tradicionalnim vrijednostima, kulturom i zavičajnim jezikom. „Zavičaj je mjera i model za sve što će se kasnije učiti“( Šimleša, 1975, str. 25). Nacionalni kurikulm za rani i predškolski odgoj (2014, str. 19)kao temeljne vrijednosti ističe „čuvanje i razvijanje nacionalne, duhovne, materijalne i prirodne baštine." Novija istraživanja naglašavaju da kulturne običaje i zavičajne vrijednosti utemeljene u djetinjstvu čovjek nosi cijeli život. U kasnijoj dobi, „kad sva druga sjećanja izblijede, sjećamo se pjesmica naučenih u ranom djetinjstvu, u obitelji ili u vrtiću“ (Cohen, 2011, str. 5). Uvrštanje zavičajnosti u kurikulume nužno je da bismo današnje mlade generacije pripremili za život u europskim okvirima zajednice više naroda, kultura i vjera, za bolje razumijevanje drugoga iz perspektive interkulture (Šuvar, 2015, Del Core, 2016). Upoznavanje kulturne baštine i zavičajnih vrijednosti od najranijeg djetinjstva najbolji je način da je sačuvamo ne samo od protoka vremena već i od nas samih. Djeca su već odavno prepoznata kao najbolji čuvari baštine.

\section{Metoda}

\section{Cilj istraživanja}

Cilj je istraživanja utvrditi stavove roditelja i odgojitelja dječjih vrtića središnje Istre o implementaciji zavičajnosti u kurikulume ustanova ranog i predškolskog odgoja.

Zadatci istraživanja su sljedeći:

1. ispitati stavove roditelja o uvođenju zavičajnosti u kurikulume ustanova ranog $i$ predškolskog odgoja

2. ispitati stavove odgojitelja o uvođenju zavičajnosti u kurikulume ustanova ranog i predškolskog odgoja. 
TEORIJSKI I PRAKTIČNI PROBLEMI I RASPRAVE

\section{Hipoteze istraživanja}

S obzirom na cilj i zadatke istraživanja hipoteze su:

H1 Roditelji smatraju važnim uvođenje zavičajnosti u kurikulum ranog i predškolskog odgoja

H2 Odgojitelji smatraju važnim uvođenje zavičajnosti u kurikulume ranog i predškolskog odgoja

H3 Odgojitelji procjenjuju važnim dodatnu educiranost i podršku kolega, ravnatelja i lokalne zajednice za provođenjem zavičajnosti u dječjim vrtićima.

\section{Sudionici istraživanja}

Istraživanje je provedeno u dvama dječjim vrtićima središnje Istre ( DV „Rapčići“ Žminj i DV „Grdelin“ Buzet). Ispitivanjem je obuhvaćeno 30 odgojitelja i 80 roditelja.

\section{Postupak istraživanja}

Ispitivanje je provedeno tijekom ožujka 2019. godine. Za potrebe istraživanja konstruiran je anketni upitnik za roditelje i odgojitelje i trostupanjska Likertova skala sudova. Podaci su obrađeni uz uporabu programa SPSS For Windows. Deskriptivni podaci prikazani su u obliku frekvencija i postotaka te aritmetičkih sredina i standardnih devijacija. Kod varijabli izraženih u kategorijama za ispitivanje značajnosti razlika korišten je Hi-kvadrat test, dok je za kontinuirane varijable primjenjivan t-test za nezavisne uzorke. Razina statističke značajnosti postavljena je na $95 \%(p<0,05)$. Sve statističke analize provedene su koristeći statistički softver SPSS 16 (SPSS Inc., Chicago, IL, USA).

\section{RezULtATI}

\section{Sociodemografske karakteristike sudionika istraživanja}

$\mathrm{U}$ istraživanju je sudjelovalo ukupno 110 sudionika, od toga 30 (27,3\%) odgojitelja i 80 $(72,7 \%)$ roditelja. U skupini roditelja obuhvaćeno je 20 (25\%) očeva i 60 (75\%) majki, dok su u skupini odgojitelja svi sudionici bili ženskog spola. Najveći broj odgojiteljica, njih 28 (93,3\%), imalo je višu stručnu spremu, dok je $1(3,3 \%)$ odgojiteljica imala visoku stručnu spremu, a također jedna (3,3\%) imala je završen magisterij ili doktorat. U skupini roditelja najzastupljenija je srednja stručna sprema koju ima $34(42,5 \%)$ ispitanika, slijedi $25(31,3 \%)$ ispitanika s visokom stručnom spremom, $19(23,8 \%)$ s višom stručnom spremom te $2(2,5 \%)$ ispitanika koji imaju magisterij ili doktorat. Najveći broj odgojiteljica, njih 12 (23,3\%) ima radni staž u trajanju od 11 do 20 godina, slijedi $8(26,7 \%)$ odgojiteljica s više od 30 godina radnog staža te $7(23,3 \%)$ odgojiteljica sa stažem od 0 do 10 godina, dok samo 3 (10\%) odgojiteljice imaju radni staž u trajanju od 21 do 30 godina (Tablica 1.). 
Tablica 1. Prikaz osnovnih sociodemografskih karakteristika ispitanika

\begin{tabular}{|l|c|c|}
\hline Spol & $\begin{array}{c}\text { Odgojitelji } n=30 \\
\mathrm{n}(\%)\end{array}$ & $\begin{array}{c}\text { Roditelji } \mathrm{n}=80 \\
\mathrm{n}(\%)\end{array}$ \\
$\begin{array}{l}\text { Muškarci } \\
\text { Žene }\end{array}$ & $0(0)$ & $20(25)$ \\
\hline Stručna sprema & $30(100)$ & $60(75)$ \\
Srednja stručna sprema & & \\
Viša stručna sprema & & $34(42,5)$ \\
Visoka stručna sprema & $28(93,3)$ & $19(23,8)$ \\
Magisterij/Doktorat & $1(3,3)$ & $25(31,3)$ \\
\hline Radni staž u dječjem vrtiću & $1(3,3)$ & $2(2,5)$ \\
0-10 godina & $7(23,3)$ & \\
11-20 godina & $12(40)$ & \\
21-30 godina & $3(10)$ & \\
31+ godina & $8(26,7)$ & \\
\hline
\end{tabular}

\section{Upoznatost odgojitelja i roditelja s pojmom zavičajnosti}

Svi ispitani odgojitelji kao i svi roditelji izjavljuju da su upoznati s pojmom zavičajnosti. Za pojam zavičajnosti roditelji su najčešće saznali iz medija, tijekom školovanja djece, dok su odgojiteljice s navedenim pojmom također najčešće upoznate putem medija i tijekom školovanja te manifestacija i priredbi u gradu (Tablica 2).

Tablica 2. Prikaz upoznatosti odgojitelja i roditelja s pojmom zavičajnosti

\begin{tabular}{|c|c|c|}
\hline & $\begin{array}{c}\text { Odgojitelji } n=30 \\
n(\%)\end{array}$ & $\begin{array}{c}\text { Roditelji } n=80 \\
n(\%)\end{array}$ \\
\hline $\begin{array}{l}- \text { da } \\
\text { - ne }\end{array}$ & $\begin{aligned} 30 & (100) \\
0 & (0)\end{aligned}$ & $\begin{aligned} 80 & (100) \\
0 & (0)\end{aligned}$ \\
\hline $\begin{array}{l}\text { Na koji su način upoznati s } \\
\text { pojmom zavičajnosti: } \\
\text { - u medijima } \\
\text { - tijekom školovanja } \\
\text { - od djece } \\
\text { - na manifestacijama } \\
\text { - negdje drugdje }\end{array}$ & $\begin{aligned} 18 & (60) \\
5 & (16,7) \\
0 & (0) \\
4 & (13,3) \\
3 & (10)\end{aligned}$ & $\begin{aligned} 51 & (63,7) \\
17 & (21,3) \\
9 & (11,3) \\
3 & (3,8) \\
0 & (0)\end{aligned}$ \\
\hline
\end{tabular}

\section{Stavovi roditelja o uvođenju zavičajnosti u kurikulume ustanova ranog i predškolskog odgoja i obrazovanja}

U Tablici 3. prikazane su frekvencije odgovora roditelja na pitanja koja ispituju stavove o uvođenju zavičajnosti u kurikulume ustanova rane i predškolske dobi, očuvanju zavičajne 
kulture i tradicijskih vrijednosti te koliko njegovanje zavičajnosti u vrtićima olakšava djetetu boravak u vrtiću.

Tablica 3. Prikaz frekvencija odgovora roditelja na pitanja koja ispituju stavove o zavičajnosti

\begin{tabular}{|l|l|l|l|}
\hline \multicolumn{1}{|c|}{$\mathrm{N}=80$} & \multicolumn{1}{|c|}{$\begin{array}{c}\text { Nevažno } \\
\mathrm{n}(\%)\end{array}$} & \multicolumn{1}{|c|}{$\begin{array}{c}\text { Važno } \\
\mathrm{n}(\%)\end{array}$} & $\begin{array}{c}\text { Vrlo važno } \\
\mathrm{n}(\%)\end{array}$ \\
\hline 1. Upoznavanje zavičaja & $0(0)$ & $10(12,5)$ & $70(87,5)$ \\
\hline 2. Poznavanje zavičajne kulture & $0(0)$ & $15(18,8)$ & $65(81,3)$ \\
\hline 3. Čuvanje tradicijskih vrijednosti & $1(1,3)$ & $12(15)$ & $67(83,8)$ \\
\hline 4. Očuvanje izvornog dijalektalnog govora & $1(1,3)$ & $10(12,5)$ & $69(86,3)$ \\
\hline 5. Prenošenje znanja i iskustva starijih osoba & $1(1,3)$ & $21(26,3)$ & $58(72,5)$ \\
\hline 6. Sadržaji zavičajnosti okupljaju cijelu obitelj & $7(8,8)$ & $32(40)$ & $41(51,2)$ \\
\hline 7. Uvođenje zavičajnih vrijednosti u programe vrtića & $1(1,3)$ & $27(33,8)$ & $52(65)$ \\
\hline 8. Olakšava djetetu boravak u dječjem vrtiću & $9(11,3)$ & $35(43,8)$ & $36(45)$ \\
\hline 9. Utječe na očuvanje kulturnog identiteta & $0(0)$ & $16(20)$ & $64(80)$ \\
\hline
\end{tabular}

Od navedenih tvrdnji kao najvažnije segmente zavičajnosti roditelji izdvajaju „upoznavanje zavičaja“ (87,5\% odgovora vrlo važno), „očuvanje izvornog dijalektalnog govora“ (86,3\% odgovora vrlo važno) te „čuvanje tradicijskih vrijednosti“ (83,8\% odgovora vrlo važno).

Ukupan prosječni rezultat stavova roditelja o zavičajnosti iznosio je Ar.sr $=2,70$ (SD $=$ 0,32 ; raspon $=1,33-3$ ).

Očevi u odnosu na majke ne razlikuju se statistički značajno u stavovima o uvođenju zavičajnosti u vrtiće $(t=1,05 ; p=0,30)$.

\section{Stavovi odgojitelja o uvođenju zavičajnosti u kurikulume ustanova ranog i predškolskog odgoja}

Na pitanje smatrate li potrebnim uvesti program zavičajnosti u kurikulume ustanova ranog i predškolskog odgoja i obrazovanja, većina ispitanih odgajatelja, njih 22 (73,3\%) odgovara potvrdno.

U Tablici 4. prikazane su frekvencije odgovora odgojitelja na pitanja koja ispituju stavove o uvođenju zavičajnosti u kurikulume ustanova rane i predškolske dobi, očuvanju zavičajne kulture i tradicijskih vrijednosti te koliko njegovanje zavičajnosti u vrtićima olakšava djetetu boravak u dječjem vrtiću. Prikazani su i stavovi odgojitelja o potrebi dodatne educiranosti te o važnosti podrške ravnatelja, kolega i lokalne zajednice u provođenju projekta zavičajnosti. 
Tablica 4. Prikaz frekvencija odgovora odgojitelja na pitanja koja ispituju stavove o zavičajnosti te potrebu za dodatnom edukacijom i podrškom

\begin{tabular}{|l|c|c|c|}
\hline \multicolumn{1}{|c|}{$\mathrm{N}=30$} & $\begin{array}{c}\text { Nevažno } \\
\mathrm{n}(\%)\end{array}$ & \multicolumn{1}{|c|}{$\begin{array}{c}\text { Važno } \\
\mathrm{n}(\%)\end{array}$} & $\begin{array}{c}\text { Vrlo važno } \\
\mathrm{n}(\%)\end{array}$ \\
\hline 1. Upoznavanje zavičaja & & $13(43,3)$ & $17(56,7)$ \\
\hline 2. Poznavanje zavičajne kulture & & $15(50)$ & $15(50)$ \\
\hline 3. Čuvanje tradicijskih vrijednosti & $1(3,3)$ & $11(36,7)$ & $18(60)$ \\
\hline 4. Očuvanje izvornog dijalektalnog govora & $1(3,3)$ & $11(36,7)$ & $18(60)$ \\
\hline 5. Prenošenje znanja i iskustva starijih osoba & $1(3,3)$ & $14(46,7)$ & $15(50)$ \\
\hline 6. Sadržaji zavičajnosti okupljaju cijelu obitelj & $8(26,7)$ & $14(46,7)$ & $8(26,7)$ \\
\hline 7. Uvođenje zavičajnih vrijednosti u programe vrtića & $7(23,3)$ & $18(60)$ & $5(16,7)$ \\
\hline 8. Olakšava djetetu boravak u dječjem vrtiću & $11(36,7)$ & $14(46,7)$ & $5(16,7)$ \\
\hline 9. Utječe na očuvanje kulturnog identiteta & $3(10)$ & $18(60)$ & $9(30)$ \\
\hline $\begin{array}{l}\text { 10. Odgojitelji koji provode program zavičajnosti } \\
\text { moraju biti posebno educirani }\end{array}$ & $4(13,3)$ & $21(70)$ & $5(16,7)$ \\
\hline $\begin{array}{l}\text { 11. Provoditi program zavičajnosti uz pomoć } \\
\text { ravnatelja, kolega, roditelja i lokalne zajednice }\end{array}$ & $4(13,3)$ & $15(50)$ & $11(36,7)$ \\
\hline
\end{tabular}

Od navedenih tvrdnji kao najvažnije segmente zavičajnosti odgojitelji izdvajaju „čuvanje tradicijskih vrijednosti“ (60\% odgovora vrlo važno), "očuvanje izvornog dijalektalnog govora“ (60\% odgovora vrlo važno) te "upoznavanje zavičaja“ (56,7\% odgovora vrlo važno). Odgojitelji najmanje važnim tvrdnjama smatraju kako zavičajnost "olakšava djetetu boravak u vrtiću“ (36,7\% odgovora nevažno) te kako „sadržaji zavičajnosti okupljaju cijelu obitelj“ ( $26,7 \%$ odgovora nevažno).

Ukupan prosječni rezultat stavova odgojitelja o zavičajnosti iznosio je $\operatorname{Ar} . s r=2,29$ $(\mathrm{SD}=0,51$; raspon $1,22-3)$.

\section{Razlike između odgojitelja dvaju ispitivanih dječjih vrtića u procjeni važnosti uvođenja zavičajnosti u kurikulume dječjih vrtića, važnosti dodatne edukacije te važnosti podrške kolega i zajednice}

U Tablici 5. prikazane su razlike odgojitelja Dječjeg vrtića „Rapčići“ Žminj i Dječjeg vrtića "Grdelin“ Buzet u ukupnom prosječnom rezultatu stavova o važnosti uvođenja zavičajnosti u kurikulume vrtića, o važnosti dodatne edukacije te o važnosti podrške ravnatelja, kolega i lokalne zajednice. 
Tablica 5. Prikaz razlika u stavovima odgojitelja obuhvaćenih vrtića o zavičajnosti, dodatnoj edukaciji i podršci okoline

\begin{tabular}{|l|c|c|c|c|}
\hline & $\begin{array}{c}\text { "Rapčići“ Žminj } \\
\mathrm{n=10} \\
\text { Ar.sr (SD) }\end{array}$ & $\begin{array}{c}\text { "Grdelin“ } \\
\text { Buzet } \mathrm{n=20} \\
\text { Ar.sr (SD) }\end{array}$ & $\mathrm{t}$ & $\mathrm{p}$ \\
\hline $\begin{array}{l}\text { Procjena važnosti uvođenja zavičajnosti u } \\
\text { kurikulume dječjeg vrtića }\end{array}$ & $2,42(0,46)$ & $2,22(0,53)$ & 1,02 & 0,317 \\
\hline Važnost dodatne edukacije & $2,30(0,48)$ & $1,90(0,55)$ & 1,94 & 0,062 \\
\hline $\begin{array}{l}\text { Važnost podrške ravnatelja, kolega i } \\
\text { lokalne zajednice. }\end{array}$ & $2,60(0,52)$ & $2,05(0,69)$ & 2,23 & 0,034 \\
\hline
\end{tabular}

Odgojitelji Dječjeg vrtića „Rapčići“ Žminj i Dječjeg vrtića „Grdelin“ Buzet ne razlikuju se u ukupnom prosječnom rezultatu stavova o važnosti uvođenja zavičajnosti u kurikulume dječjeg vrtića ni u procjeni važnosti dodatne edukacije glede provođenja programa zavičajnosti. Odgojitelji navedenih dvaju dječjih vrtića razlikuju se međutim u procjeni važnost podrške ravnatelja, kolega i lokalne zajednice: zaposlenici Dječjeg vrtića „Rapčići“ Žminj procjenjuju važnost podrške statistički značajno višom u usporedbi s odgojiteljima Dječjeg vrtića „Grdelin“ Buzet $(t=2,23 ; p=0,034)$

\section{RASPRAVA}

Odgoj i obrazovanje temelje se na najvišim ljudskim vrijednostima, baštine zemlje u kojoj dijete živi. Provedena istraživanja upućuju na nužnost uvrštanja kulturne baštine u kurikulume odgojno-obrazovnih ustanova (Townsend-Cross, 2004; Windisch i sur., 2003; Rosandić, 1975; Šimleša, 1975; Maršić, 2007; Katalinčić, 2007; Meštrić i Ferić, 2006; Cifrić, 2014; KostovićVranješ i Kuščević, 2015). Provedenimistraživanjem nastojalo se utvrditi podržavaju li roditelji i odgojitelji uvrštanje zavičajnosti u kurikulume ustanova ranog i predškolskog odgoja u Istarskoj županiji. Potvrđene su sljedeće hipoteze:

\section{H1 Roditelji smatraju važnim uvođenje zavičajnosti u kurikulum ranog i predškolskog odgoja}

Od navedenih tvrdnji upoznavanje zavičaja $87,5 \%$ roditelja procjenjuje vrlo važno, a $12,5 \%$ važno. Nitko od roditelja ne smatraupoznavanje zavičaja nevažnim. Vrlo visoko roditelji rangiraju očuvanje izvornog dijalektalnog govora sa $86,3 \%$ vrlo važno i $12,5 \%$ važno, samo se jedan roditelj izjasnio da je očuvanje dijalekta nevažno. Da je očuvanje tradicijskih vrijednosti vrlo važno, smatra $83,8 \%$, a važnim naglašava $15 \%$ roditelja, dok samo jedan roditelj smatra nebitnim. Rezultati provedenog istraživanja korespondiraju s rezultatima istraživanja o važnosti tradicionalnih igara i zavičajnog jezika u ustanovama ranog i predškolskog odgoja i obrazovanja (Wendisch i sur., 2003). Povijest, jezik, umjetnost, tradicijski običaji, vrijednosti sredine u kojoj djeca žive i odrastaju moraju biti i sastavni dio kurikuluma, posebno ističući upravo aspekt kulture u njihovom prirodoslovnom obrazovanju (Huang i Liu 2017).Do istih spoznaja u svojim istraživanjima dolaze i Tan, Liu, i You (2008), Chinn (2007), Gay (2000), Škrgulja (2007), Maretić, Cakatoš (2007). Poznavanje zavičajne kulture $81,3 \%$ roditelja smatrada je vrlo važno, a $18,8 \%$ smatra da je važno za njihovo dijete, isto tako $80 \%$ roditelja smatra da je očuvanje kulturnog identiteta vrlo važno, a $20 \%$ smatra da je važno. Nitko od roditelja ne smatra ta dva segmenta zavičajnosti nevažnim. Bronfenbrenner (1979) u Rogoff (1990) naglašavaju da je individualni razvoj djeteta uvjetovan kulturnim i društvenim kontekstom u kojem se odvija, što podupire 
studija o Djeci u šest kultura (Whiting i Whiting, 1975)naglašavajući važnost povijesnih tradicija i okoline kojima se roditelji vode u odgoju svoje djece. Očekivalo se da će roditelji tvrdnju sadržaji zavičajnosti okupljaju cijeluobitelj visoko podržavati, no ona je tek na osmom mjestu sa $51,2 \%$ odgovora vrlo važno dok $40 \%$ roditelja smatra važnim, a čak $8,8 \%$ roditelja smatra nevažnim. Nisu primijećene statistički značajne razlike u stavovima između očeva i majki o uvođenju zavičajnosti u kurikulume dječjih vrtića.

\section{H2 Odgojitelji smatraju važnim uvođenje zavičajnosti u kurikulume ranog i predškolskog odgoja}

U pitanjima koja se odnose na stavove odgojitelja o uvođenju zavičajnosti u kurikulume kao najvažniji segment $60 \%$ odgojitelja izdvaja čuvanje tradicijskih vrijednosti vrlo važnim, $36,7 \%$ važnim, a samo 3,3\% smatra da je nebitno. Također $56,7 \%$ odgojitelja smatra da je upoznavanje zavičaja vrlo važno, dok $43,3 \%$ smatra važnim,a nitko od odgojitelja ne smatra da je upoznavanje zavičaja nebitno. Poznavanje zavičajne kulture i prenošenje znanja, vrijednosti... sa starijih na mlađe generacije 50\% odgojitelja smatra vrlo važnim, a $50 \%$ važnim. Nadalje, $36,7 \%$ odgojitelja smatra vrlo važnim podršku kolega, ravnatelja, roditelja u provođenju zavičajnosti, $50 \%$ smatra važnim, a $13,3 \%$ smatra nebitnim. Da poznavanje zavičajnih vrijednosti utječe na očuvanje kulturnog identiteta, kao vrlo važno procjenjuje $30 \%$ odgojitelja, važnim smatra $60 \%$, dok $10 \%$ odgojitelja smatra da je to nebitno. Roditelji navedeni segment procjenjuju znatno važnijim od odgojitelja pa tako $80 \%$ roditelja smatra vrlo važnim, a $20 \%$ važnim. Nitko od roditelja ne misli da je očuvanje kulturnog identiteta za njihovo dijete nebitno. Preuzimanje vrijednosti drugih kultura, jedinstvenih metodologija i programa kvalificiranim kao „najbolje prakse“ temeljene na autoritetu eurozapadne znanosti, mogu potisnuti u zaborav vlastito kulturno naslijeđe (Ball, 2010;Burton, 2012). Rezultati provedenog istraživanja korespondiraju s rezultatima istraživanja koje su provele Windisch, Jenvej i Drysdale (2003) o važnosti tradicionalnih igara u obrazovanju djece predškolske dobi.

\section{H3 Odgojitelji procjenjuju važnim dodatnu educiranost i podršku kolega, ravnatelja i lokalne zajednice za provođenje zavičajnosti u dječjim vrtićima.}

Očekivalo da će odgojitelji procijeniti vrlo važnim uvođenje zavičajnosti u kurikulume dječjeg vrtića, osposobljenost i podršku kolega, ravnatelja i lokalne zajednice. Odgojitelji dječjeg vrtića „Rapčići“ Žminj i „Grdelin“ Buzet se u ukupnom prosječnom rezultatu stavova o važnosti uvođenja zavičajnosti u kurikulume vrtića i dodatne educiranosti odgojitelja ne razlikuju statistički, što je i očekivano s obzirom da su i jedan i drugi vrtić u relativno malim sredinama u kojima je dominantno autohtono stanovništvo. Međutim, odgojitelji dječjeg vrtića Žminj procjenjuju važnost podrške statistički značajno višom Ar.sr 2,60 (SD 0,52) u odnosu na odgojitelje u dječjem vrtiću Buzet Ar. sr 2,05 (SD 0,69). Istraživanja potvrđuju povezanost između otuđenosti pojedinca i sve prisutnijem distanciraju od tradicionalnih vrijednosti izostavljanjem tema koje se odnose na kulturnu baštinu iz školskih programa, a gubitak kulturne baštine rezultira gubitkom kulturnog identiteta i osiromašenjem u mnogim aspektima života (Kokko i Kyritsi, 2012). Nužnost uvođenja kulturne baštine i zavičajnih sadržaja u kurikulume vrtića podupire i studija Cole i sur. ${ }^{3}$ ističući kako kultura oblikuje iskustvo i utječe na razvoj djeteta, odnosno kultura utječe na to kako djeca poimaju svijet, a „dijete već od samog rođenja poznaje karakterističnu melodiju svog materinskog jezika"(Cole i sur., 2010, str. 2). Kulturna baština u znanstvenoj i stručnoj literaturi prepoznata je kao važan aspekt interkulturne komunikacije i održivog razvoja.

Cilj je provedene studijebio pokazati kako su tradicijske vrijednosti i razvoj djeteta povezani, kako se ti utjecaji očituju na razvoj djeteta, kako različite kulturne tradicije oblikuju dječje učenje i kako utječu na djecu migranata. 


\section{ZAKUUČAK}

Cilj provedenog istraživanja bioje utvrditi podržavaju li roditelji i odgojitelji te u kojoj mjeri uvrštanje zavičajnosti u kurikulume dječjih vrtića. Unatoč relativno skromnomuzorku sudionika istraživanja roditelja i odgojitelja, utvrđena je visoka podrška svih ispitanika uvrštanju zavičajnosti u kurikulum. Međutim, odgojitelji u dvama dječjim vrtićima statistički se značajno razlikuju u procjeni važnosti podrške kolega, ravnatelja i lokalne zajednice. Rezultati impliciraju na mali broj znanstvenih istraživanja koja se bave implementacijom zavičajnosti u odgojnoobrazovani proces, posebno u ranom i predškolskom odgoju. Isto tako, rezultati ukazuju na potrebu daljnjeg istraživanja tog problema i razvoj dodatnih standardiziranih instrumenata za ispitivanje kojima bi se dobili precizniji podaci kontinuiranog rada na očuvanju kulturne baštine i zavičajnih vrijednosti. Brojni su primjeri iz pedagoške prakse (potvrđeni znanstvenim istraživanjima) da su upravo djeca prepoznata kao najbolji čuvari zavičajnih vrijednosti i kulturne baštine. Stoga se čini potrebnim istaknuti nužnost implementacije zavičajnosti u kurikulume ranog i predškolskog odgoja i obrazovanja.

\section{LITERATURA}

Anić, V. ( 2009). Veliki rječnik hrvatskog jezika. Zagreb: Novi Liber.

Anić, V. (2003). Veliki rječnik hrvatskog jezika. Zagreb: Novi Liber.

Ball, J. (2010). Culture and Early Childhood Education. Enciklopedia on Early Cildhood

Development.

Bronfenbrenner, U. (1979). The ecology of human evelopment. Cambridge, MA: Harvard University Press.

Burton, L. J. (2012). Building on Living Traditions: Early Childhood Education and Culture in Solomon Islands. Current Issues in Comparative Education, Teachers College, Columbia University, 15(1), 157-175.

Chinn, P. W. U. (2007). Decolonizing methodologies and Indigenous knowledge: The role of culture, place and personal experience in professional development. Journal of Research in Science Teaching, 44(9), 1247-1268.

Cifrić, I. (2014). Očuvanje baštine u kontekstu Europske unije. Zagreb: Adrias, 20, 9-19.

Cohen, B. (2011). Razumjeti sebe i druge: važnost mjesta odrastanja i vlastitog identiteta u multikulturalnom društvu. Dijete vrtić obitelj, Zagreb: Korak po korak, 17(65), 2-5.

Cohen, L., Manion, L. i Morrison, K. (2007). Metode istraživanja u obrazovanju. Zagreb: Naklada Slap.

Cole, M., Hakkarainen, P. i Bredikyte, M. (2010). Culture and Early Childhood Learning. U: Encyclopedia on Early Childhoode Development.

Del Core, P. ( 2016). Rapporto tra identità e cultura, una coordinata essenziale per «comprendere l'altro» nella prospettiva dell'intercultura. Preuzeto s https://educa.fmleao.pt/no2-2016/ rapporto-tra-identita-e-cultura-una-coordinata-essenziale-per-comprendere-laltro-nellaprospettiva-dellintercultura-2/, 5.1.2019.

Gay, G. (2000). Culturally responsive teaching: Theory, research, and practice. New York: Teachers College Press.

Huang, T. H. i Liu, Y. C. (2017). Science Education Curriculum Development Principles in Taiwan: Connecting with Aboriginal Learning and Culture. Euroasia: Journal of Mathematics Science and Technology Education, 13(5), 1341-1360.

Katalinič, D. (2007). Odnos prema baštini počinje u vrtiću. Didaktički vidici prirodoslovne baštine u povezanosti s ekologijomu predškolskome odgoju. U: N. Cambi (ur.), Zavičajna baština HNOS $i$ kurikulum (str. 251-254). Split: Književni krug. 
Kokko, S. Kyritsi, A. (2012). Cultural Heritage Education for Intercultural Communication. Preuzeto s https://www.researchgate.net/publication/274867662, 19.1.2019.

Konvencija o pravima djeteta (1989). Ujedinjeni narodi Preuzeto s http://www.dijete.hr/index. php?option=com_contentiview=articleiid=107, 13.3.2019.

Kostović-Vranješ, V. (2015). Baština - polazište za promicanje odgoja i obrazovanja za održivi razvoj. Školski vjesnik,

Kuščević, D. (2015). Kulturna baština - poticatelj dječjeg razvoja (likovni aspekt).Školski vjesnik, 479491.

Maretić, M. i Caktaš, J. (2007). Zavičajna baština u funkciji očuvanja hrvatskog identiteta. U: N. Cambi (ur.), Zavičajna baština HNOS i kurikulum (str. 87-96), Split: Književni krug.

Maršić, I.(2007). HNOS - Nova obrazovna paradigma. U: N. Cambi (Ur.), Zavičajna baština HNOS $i$ kurikulum. Split: Književni krug, 193-201.

Meštrić, K. B. i Ferić, K. (2006). Pregrad, J. (ur.) Okvirni kurikulum za predmet kulturna i duhovna baština zavičaja. Osijek: Nansen dijalog centar.

Nacionalni kurikulum za rani i predškolski odgoj i obrazovanje (2014). Zagreb: Ministarstvo znanosti, obrazovanja i sporta.

Puamau, P. (2005). Rethinkingeducational reform: Pacific perspective. Paper presented at the international conference „Redesigning pedagogy: Research, policy and practice," National Institute of aducation, Naniyang Technological University, Singapore

Rogoff, B. (1990). Apprenticeship in thinking: Cognitive development in social contekst. Oxford, UK: Oxford University Press.

Rosandić, D. (1975). Za afirmaciju načela zavičajnosti u nastavi književnosti. U: M. Kalčić (ur.), Zavičajna književnost u nastavi (str. 9-17). Žminj: Čakavski sabor.

Rubin, K. H. i Menzer, M. (2010.) Culture and Social Development. Encyclopedia on Early Childhood Development.

Službeni list Europske unije L 131/1. Odluka europskog parlamenta i Vijeća europe (2017). Preuzeto s https://eur-lex.europa.eu/legal content/EN/TXT/?uri=CELEX\%3A32017D0864, 20.2.2019.

Škrgulja, V. P. (2007). Baština u školi popularizacija sustavne skrbi za baštinu zavičaja u manjoj lokalnoj sredini - iskustvo iz Ivanić Grada. U: N. Cambi (ur.), Zavičajna baština HNOS i kurikulum (str. 203-223), Split: Književni krug.

Šimleša, P. (1975). Načelo zavičajnosti kao aspekt povezanosti škole sa životom. U: M. Kalčić (ur.), Zavičajna književnost u nastavi (str. 19-28), Žminj: Čakavski sabor.

Šošić, T. M. (2014). Pojam kulturne baštine - međunarodno pravni pogled, Zbornik radova Pravnog fakulteta u Splitu, 51(4), 833-860.

Šuvar, V. (2015). Zavičajni sadržaji u procesu izgradnje osobnog i kulturnog identiteta učenika. U: D. Maleš., A. Širanović., A. Višnjić-Jevtić (ur.), Pravo djeteta na odgoj i obrazovanje. Teorije, politike i prakse (str. 240-246). Zagreb: Odsjek za pedagogiju Filozofskoga fakulteta u Zagrebu OMEP Hrvatska.

Tan, K. D., Liu, M. H. i You, M. H. (2008). Multicultural Education.Taipei: Higher Education Publishing Co.

Thurley,S. (2005). Into the future. Our stategy for 2005-2010. U: Conservation Bulletin. Preuzeto s http://www.cultureindevelopment.nl/Cultural_Heritage/What_is_Cultural_Heritage, 6.1.2019.

Townsend-Cross, M. (2004). Indigenous Australian perspectives in early childhood education. International Conference and Meeting, Identities and innovations: Shaping better worlds through early child hood education, 16-19 July 2004, Melbourne.

Zakon o potvrđivanju Okvirne konvencije Vijeća Europe o vrijednosti kulturne baštine za društvo. Zagreb: Narodne Novine - međunarodni ugovori, br. 5/07 (2007).

Whiting, J. i Whiting, B. (1975). Children in six cultures: A psychocultural analysis. Cambrige, MA: Harvard University Press.

Whitington, V. (2004). Indinpendence and interdependence in early childhood services. Early childhood Australia Inc., 29(1), 14-21. 
Windisch, L. E., Jenvey, V. B. i Drysdale, M. (2003). "Indigenousparents" ratings of theimportance of play, Indigenous gamesand language, and early childhoodeducation: Sage Publications, 28(3), $50-56$.

\title{
Attitudes of Preschool Teachers and Parents on Implementation of Cultural Heritage in the Curicculum of the Preschool Institutions
}

\begin{abstract}
The Istrian County has started the process of cultural heritage classes in the curriculum in the early and preschool education, primary and high schools in 2014. The guideline of the implementation process is to preserve the local cultural values and the consciousness of cultural identity.

The goal of this research is to assert if the parents and preschool teachers support the implementation of Cultural Heritage in the curriculum of kindergartens.

The empirical data collected in the kindergartens, "Rapčići" Žminj and "Grdelin" Buzet is shown in this article. With the use of a questionnaire both parents and preschool teachers were questioned whether they support the implementation of Cultural Heritage in the curriculum and whether the education and learning about local cultural values has a positive effect on development and preservation of the cultural identity.
\end{abstract}

Keywords: children of early and preschool age, cultural heritage, curriculum, preschool teachers, parents, local cultural values

\section{Einstellungen der Eltern und Erzieher zur Heimatkunde in den Lehrplänen der Kindertages- und Vorschuleinrichtungen}

Zusammenfassung: Die Gespanschaft Istrien beginnt im Jahr 2014 mit der Implementierung der Heimatkunde in die Lehrpläne der Kindertages- und Vorschuleinrichtungen, Grund- und Mittelschulen. Der Sinn dieses Prozesses ist, die Heimatwerte und das Bewusstsein über die eigene kulturelle Identität zu bewahren.

Das Ziel dieser Untersuchung ist es, festzustellen, ob Eltern und Erzieher die Durchführung der Heimatkunde in den Kindertageseinrichtungen unterstützen und ob das Lernen über die Heimatwerte einen positiven Einfluss auf die Entwicklung und Erhaltung der kulturellen Identität ausübt. In diesem Beitrag werden die Daten einer empirischen Untersuchung, die in den Kindergärten „Rapčići“ in Žminj und "Grdelin" in Buzet durchgeführt wurde, dargestellt. Anhand eines Fragebogens haben wir die Eltern und die angestellten Erzieher befragt, und festgestellt, dass sich Eltern eher für die Einführung von Heimatkunde in die Lehrpläne äußern, bzw. diese als wichtiger erachten, als die Erzieher. Es wurde kein signifikanter Unterschied unter den Erziehern in Bezug auf deren Einschätzung der Bedeutung von Heimatwerten in den Lehrplänen von Kindertageseinrichtungen festgestellt. Jedoch stellte sich bei der Einschätzung, wie bedeutend die Unterstützung durch die Kindergartenleitung, die Kollegen und die Gemeinde ist, ein signifikanter Unterschied heraus.

Schlüsselwörter: Klein- und Vorschulkinder, Kulturerbe, Lehrplan, Erzieher, Eltern, Heimatwerte 